\title{
Effects of Aging and fast-cooling on the Mechanical Properties of Mg-14Li-3Al-3Ce alloy
}

\author{
C. O. Muga ${ }^{1}$, H. Guo ${ }^{1}$, S. S. Xu ${ }^{1}$, Z. W. Zhang* ${ }^{1}$ \\ ${ }^{1}$ Key Laboratory of Superlight Materials and Surface Technology, Ministry of \\ Education, College of Materials Science and Chemical Engineering, Harbin \\ Engineering University, Harbin 150001, P R China.
}

\begin{abstract}
Effects of aging and fast-cooling on the mechanical properties of Mg-14Li-3Al-3Ce alloy were investigated. Processing of aging and fast-cooling effectively refines microstructure and control the precipitation of intermetallics. Refined microstructures, enhanced tensile strengths and increased ductility were realized. Microstructures phase analysis depicts presence of dominant single coherent bcc $\beta$-phase and intermetallics. The as-cast Mg-14Li-3Al-3Ce alloy exhibits YS of 72.6MPa, UTS of $104.3 \mathrm{MPa}$ with ductility of 5.8\%. Mg-14Li-3Al-3Ce alloys that were aged for longer hours show higher age-hardening response than the as-cast alloy. The alloy that was aged for 15 hours depicts YS of 105.5MPa, UTS of 136.8MPa and strain of $19.2 \%$. Prolonged aging and fast-cooling activates grains/grain boundary refinement. The alloys exhibit high tensile strength after age-hardening response and fast-cooling processing. Precipitation of coherent bcc $\beta$-phase contributes to enhanced ductility where as intermetallics and strain aging enhances the tensile strength. Fast-cooling enhanced Mg-14Li-3Al-3Ce alloys strength through grain refinement, crystallization and solid solution strengthening.
\end{abstract}

Key Words: Mg-14Li-3Al-3Ce alloy, Aging, Fast-cooling, Tensile properties.

*Corresponding author:

Email: zwzhang@ @ hrbeu.edu.cn; Tel: +86-451-82568591 (Z. W. Zhang) 


\section{Introduction}

Over the last decade, greater focus has been on Magnesium-based alloys for their application in automobile, aviation and electronic industries. As one of the lightest structural materials, Magnesium-based alloys display impressive advantages of high specific strength and stiffness, excellent electromagnetic shielding and good damping characteristics[1-3]. Amongst variety of $\mathrm{Mg}$-based alloys, $\mathrm{Mg}$-Li alloys have the lowest density that ranges between $1.30-1.60 \mathrm{~g} / \mathrm{cm}^{3}$. This translates to more than $25 \%$ lighter than the conventional Magnesium alloys. Alloying Magnesium with Lithium can change the crystal structure from hexagonal close packed (hcp) to body-centred cubic (bcc), providing more accommodative slip systems[4-6]. Increasing Lithium content decreases the crystal lattice parameters ratio (c/a) of $\alpha$-phase, initiating easier slip occurrence between crystal planes[7]. In addition, Lithium addition in the binary alloy significantly favours the formability of Magnesium alloys. However, Mg-Li alloys still exhibit low tensile strength and corrosion resistance that limits their wide-range engineering applications.

To overcome these drawbacks, numerous elements have been alloyed with $\mathrm{Mg}-\mathrm{Li}$ to improve their mechanical properties[8-15]. From previous successful studies, aluminium addition increases tensile strength and hardness of $\mathrm{Mg}-\mathrm{Li}$ alloys by means of solid solution and intermetallic compounds reinforcements[15, 16]. Introducing zinc in to the alloy also improves mechanical properties because of its high solid solubility in both $\alpha$-and $\beta$-phases of Mg-Li alloys[17]. Because Rare Earth (RE) elements have been widely acknowledged as favourable additives in Magnesium alloys, many researchers have focused on enhancing the $\mathrm{Mg}$-Li based alloys with $\mathrm{RE}$ addition. Wu et al. reported that the addition of Y-rich RE remarkably improves the mechanical properties of $\mathrm{Mg}$-Li alloy[18]. Addition of Cerium element followed by subsequent heat treatment enhances 
the mechanical properties of $\mathrm{Mg}$-Li-Al alloys. Aging the alloys significantly impart superior tensile strength[19]. Other studies have shown that Equal Channel Angular Pressing (ECAP), Equal Channel Angular Extrusion (ECAE) techniques and aging promote ultrafine microstructure structure and enhance the mechanical properties of $\mathrm{Mg}$ Li alloys. Hence addition of rare earth elements and thermo-mechanical treatment is essential in improving its mechanical and structural properties[20-23]. The formation of coherent precipitates during age-hardening has also been applied to enhance effective planes and phases of Mg-based alloys. By increasing the number of nucleation sites during aging, the volume of precipitates density is enhanced, resulting in increased precipitation hardening[24, 25]. Variety methods of increasing the density of nucleation sites have been investigated, including multi-stage aging, isothermal aging treatment and $\mathrm{RE}$ addition. Multi-stage aging is extremely effective in refining $\mathrm{Mg}-\mathrm{Li}$ based alloys and precipitates. Age-hardening of the Mg-based alloys contributes to greater tensile strength[26]. This study investigates the microstructure evolution, fractogragphy and mechanical properties of Mg-14Li-3 Al-3Ce alloys after age-hardening.

\section{Experimental}

The alloys were prepared from high purity metal elements of Magnesium, Lithium, Aluminium and the Master Alloys Magnesium-30\% Cerium (purity 99.9wt. $\%)$. The alloys were melted in a steel crucible in a vacuum induction furnace at inert argon gas atmosphere. The vacuum furnace chamber was maintained at a constant pressure of $1.0 \times 10^{-1} \mathrm{~Pa}$ and a temperature of $700^{\circ} \mathrm{C}$ during the melting process. The melt was casted in a copper mould of $70 \mathrm{~mm} \times 100 \mathrm{~mm} \times 15 \mathrm{~mm}$. The as-cast samples were aged in an inert argon gas atmosphere at $280^{\circ} \mathrm{C}$ for 5,10 and 15 hours, respectively and then cooled by water quenching. The samples for microstructure observation were prepared by standard mechanical grinding and polishing procedures. Subsequent etching was 
done in $8.0 \mathrm{vol} \%$ nitric acid solution in distilled water and thoroughly rinsed using ethanol to reveal the grain boundaries.

By application of LEICA DMIRM optical microscope and JSM-6480 scanning electron microscope (SEM) equipped with EDS (JED 2200) of energy range 1-20keV, the alloys microstructures were examined. Samples for tensile test were machined from the central portions of the as-cast, aged and cooled alloys at a gauge size of $12.5 \mathrm{~mm} \times 3.50 \mathrm{~mm} \times 2.50 \mathrm{~mm}$. Tensile tests were carried out on electro-universal tester machine Instron $5500 \mathrm{R}$ with a strain rate speed of $0.50 \mathrm{~mm} / \mathrm{min}$ at room temperature. Ten different random indentations were performed by Vickers Hardness Tester (HVS$1000 \mathrm{~A}$ ) in order to investigate the alloys hardness. Values obtained were averaged for each alloy sample to enhance accuracy. Phase compositions of the alloys were identified using X-ray diffraction (XRD) with $\mathrm{Cu} \mathrm{K} \alpha$ radiation (D/MAX-A) machine and analysis done based on ICDD standard database. The composition of as-cast alloy was determined by inductively coupled plasma-atomic emission spectroscopy and listed in Table1.

Table 1: Chemical composition of as-cast $\mathrm{Mg}-14 \mathrm{Li}-3 \mathrm{Al}-3 \mathrm{Ce}$ alloy by mass fraction, $\%$ as determined by inductively coupled plasma-atomic emission spectroscopy (ICP-AES)

\begin{tabular}{|l|c|c|c|c|}
\hline Alloy & $\mathrm{Li}$ & $\mathrm{Al}$ & $\mathrm{Ce}$ & $\mathrm{Mg}$ \\
\hline Mg-14Li-3Al-3Ce & 14.21 & 3.10 & 3.16 & Bal. \\
\hline
\end{tabular}

\section{Results and discussion}

\subsection{Microstructure}

The microstructures of $\mathrm{Mg}-14 \mathrm{Li}-3 \mathrm{Al}-3 \mathrm{Ce}$ alloys under various conditions are shown in Figure 1. The phases determined by XRD are shown in Figure 2. The as-cast and aged alloys primarily consist of the $\beta$-phase as matrix embedded with $\beta-\mathrm{Mg}_{12} \mathrm{Ce}$, 
$\mathrm{Al}_{11} \mathrm{Ce}, \beta-\mathrm{Mg}_{17} \mathrm{Al}_{12}$ precipitates and excess/un-dissolved Cerium particles. Figures $1 \& 3$

(b) and (c) exhibits grains and grain boundary refinement for the alloys aged at $280^{\circ} \mathrm{C}$ for 5 hours and 10 hours, respectively. The grains/grain boundary refinement can be explained by the relative grain size (RGS) model[27]. The model quantifies the grain refinement capacity that originates from the solute content based on the equation:

$$
d_{R G S}=1-\left(\frac{m_{1} c_{0}}{m_{1} c_{0}-\Delta T_{C}}\right)^{1 / P}
$$

Where: $d_{\text {RGS }}$ represents the relative grain size of the Mg-14Li-3Al-3Ce alloy particles, $m_{1}$ is the gradient of the liquidus slop and $c_{0}$ is the concentration of the solute. $\Delta T_{c}$ is the maximum constitutional under cooling[27] and:

$$
\Delta T_{c}=m_{1} c_{0}(k-1) / k
$$

$P$ is the supercooling parameter and $P=1-k$ (with $k$ being coefficient for the solute). Grain refinement noted in $\mathrm{Mg}-14 \mathrm{Li}-3 \mathrm{Al}-3 \mathrm{Ce}$ alloy aged at $280^{\circ} \mathrm{C}$ for 15 hours followed by subsequent fast-cooling at room temperature is shown in Figure 1 (d). The formation of $\mathrm{Mg}-\mathrm{Ce}$ and $\mathrm{Al}-\mathrm{Ce}$ compounds is attributable to large electronegative difference that exists between the composite elements. Al-Ce phase reduces the $\mathrm{Al}$ atoms in the lattice hence increasing relative grain size (RGS) and improves the nucleation sites. By progressively increasing the aging time, the microstructures become more refined. It is evident that aging enhances the homogeneity of the $\mathrm{Mg}-14 \mathrm{Li}-3 \mathrm{Al}-3 \mathrm{Ce}$ alloy microstructures. The numerous white particles in Figures 1 and 3 are mainly resultant intermetallic precipitates and un-dissolved Cerium particles owing to its negligible solubility in the Magnesium-based alloys. 

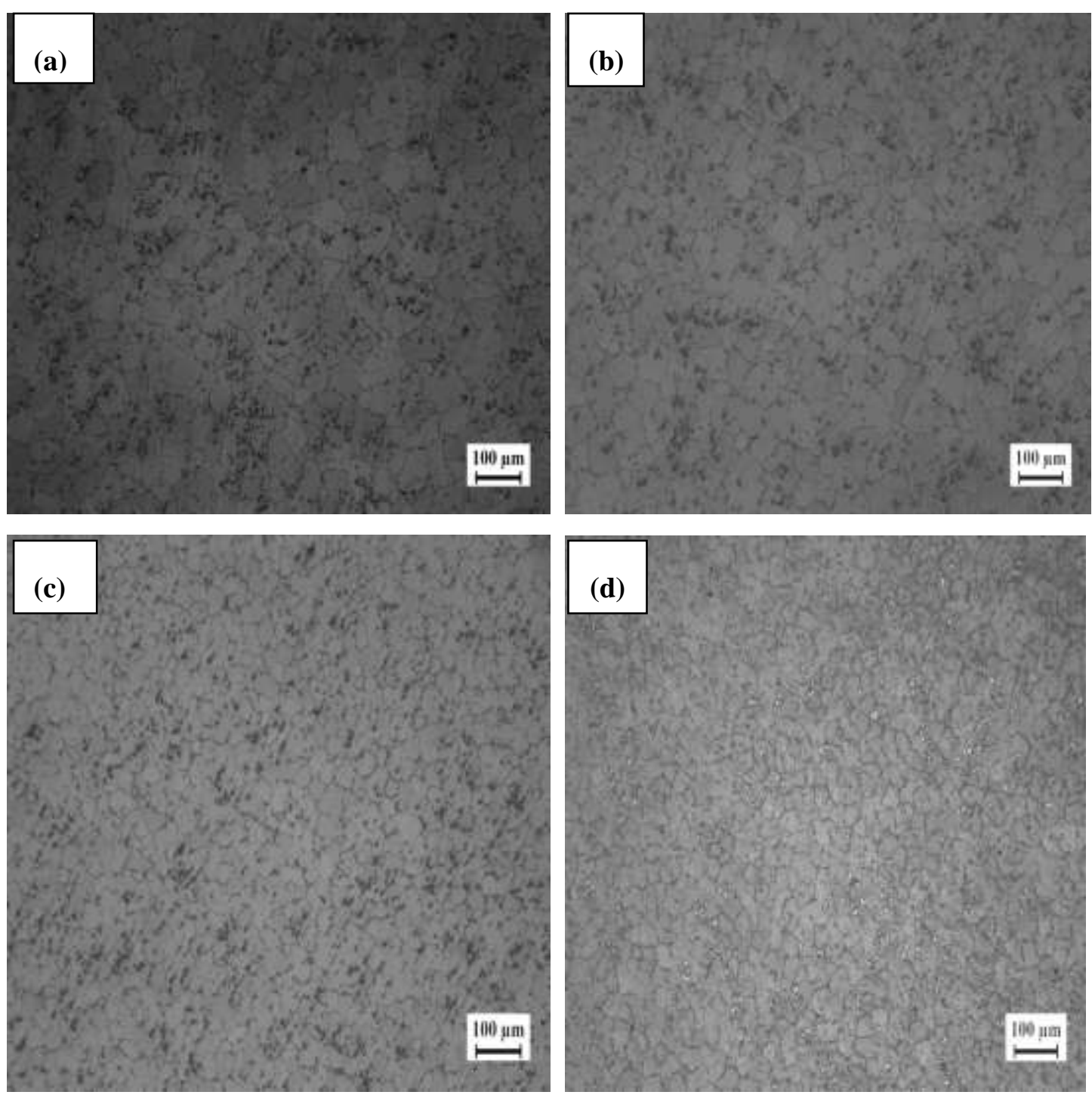

Figure1: Optical microstructures of Mg-14Li-3Al-3Ce alloys: (a) As-cast, (b) Aged for 5 hours, (c) Aged for 10 hours, (d) Aged for 15 hours 


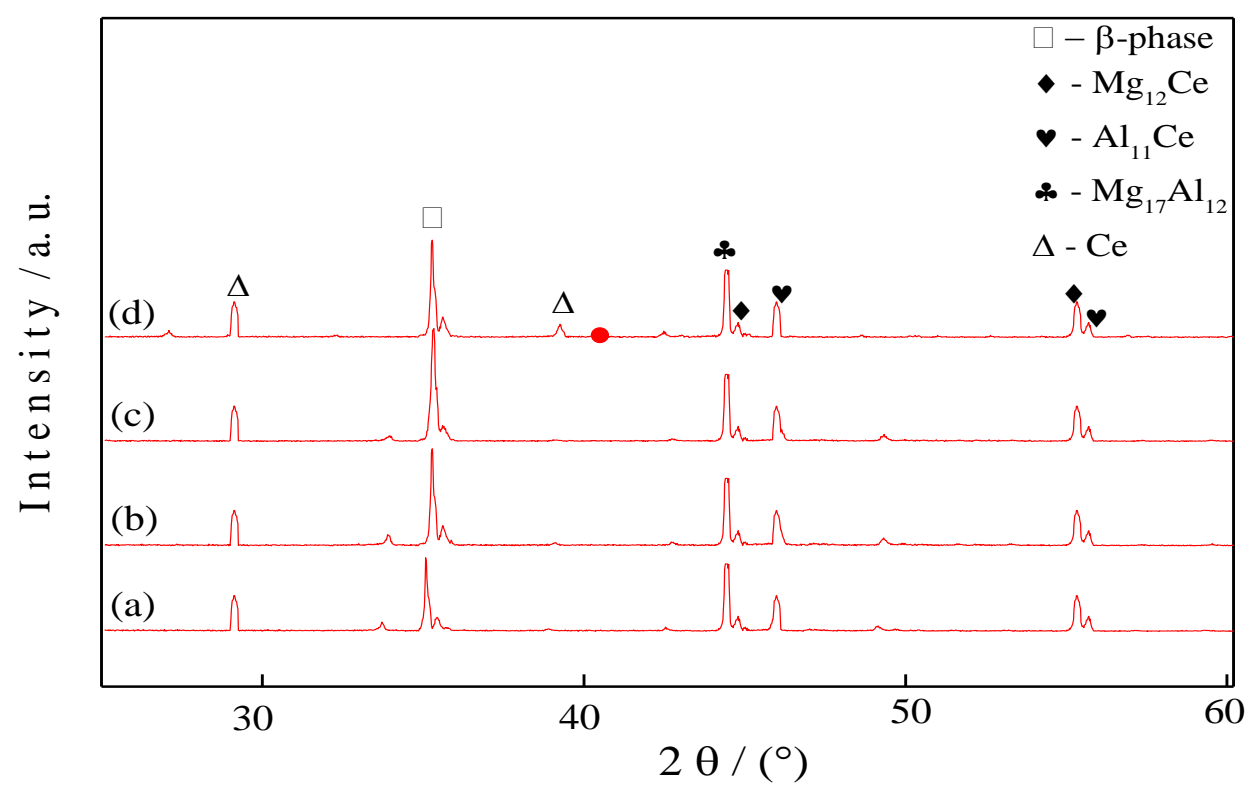

Figure 2: XRD analysis of the Mg-14Li-3Al-3Ce alloys: (a) As-cast, (b) Aged for 5 hours, (c) Aged for 10 hours, (d) Aged for 15 hours.

In order to depict the formation of phases in detail, the microstructures of the alloy under various conditions were observed by SEM, as shown in Figures 3 and 4. The eutectic transformation leads to the lamellar regions consisting of bcc $\beta$-phase and intermetallics. A reduction in the volume of the networked eutectic regions is observed in Figures 3 (b), (c) and (d). This may be attributed to the tendency to form fine precipitates as a result of the aging process. Figure 1 (d) shows onset formation of fine precipitates that result in increased nucleation sites for further continuous and discontinuous precipitations along the grain boundaries[28-30]. Figures 1 (d) and 3 (d) also exhibit the most refined microstructures owing to both aging process and fastcooling by water. This is because fast-cooling by water refines $\mathrm{Mg}-14 \mathrm{Li}-3 \mathrm{Al}-3 \mathrm{Ce}$ grains size and enhances the alloys crystallization rate during the cooling period at room temperature[31-33]. During aging, the amount of un-dissolved cerium particles decrease in some extent with the formation of Ce-contaning precipitates as depicted in Figure 3. 

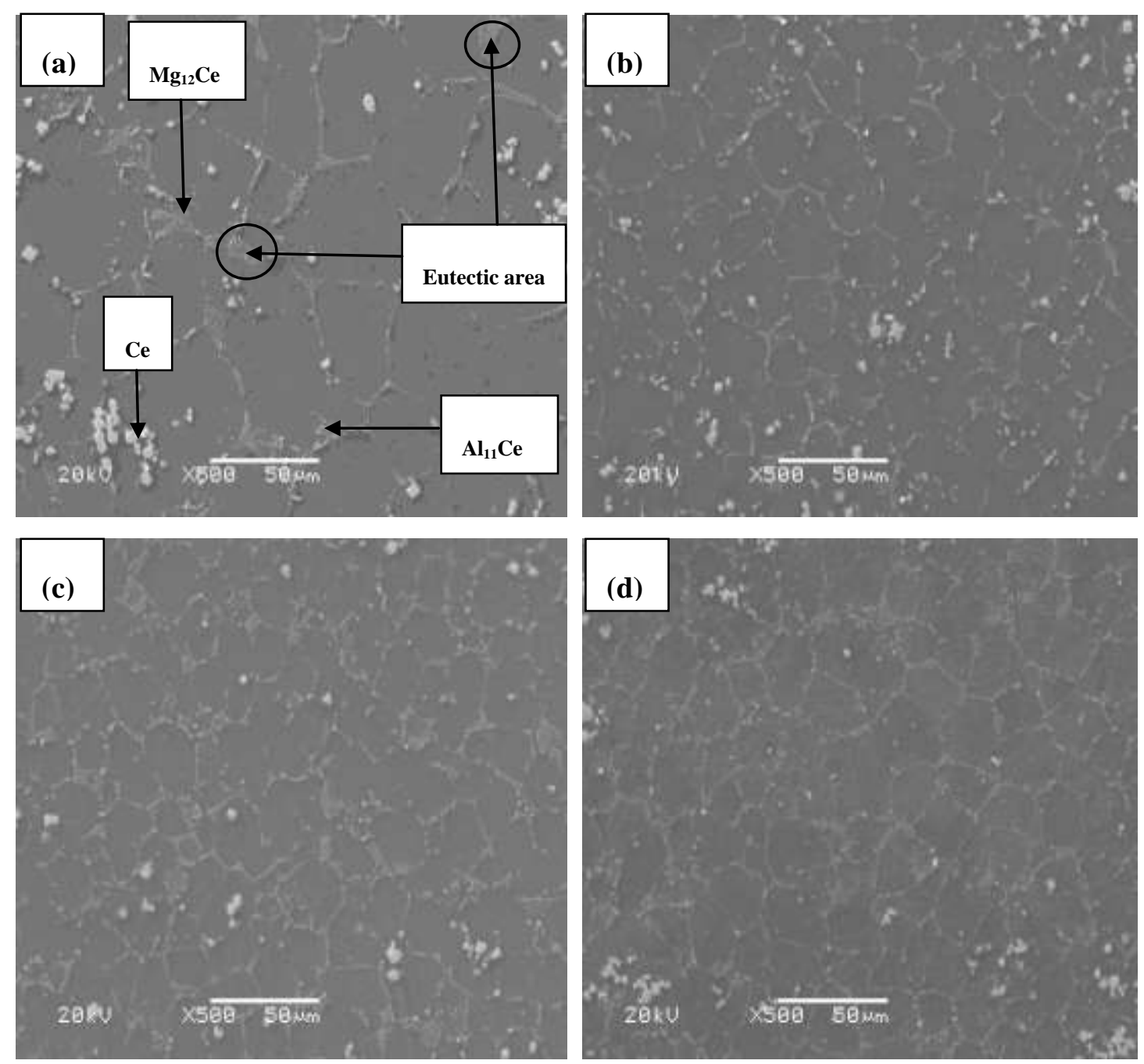

Figure 3: SEM microstructures of Mg-14Li-3Al-3Ce alloys: (a) As-cast, (b) Aged for 5 hours, (c) Aged for 10 hours, (d) Aged for 15 hours.
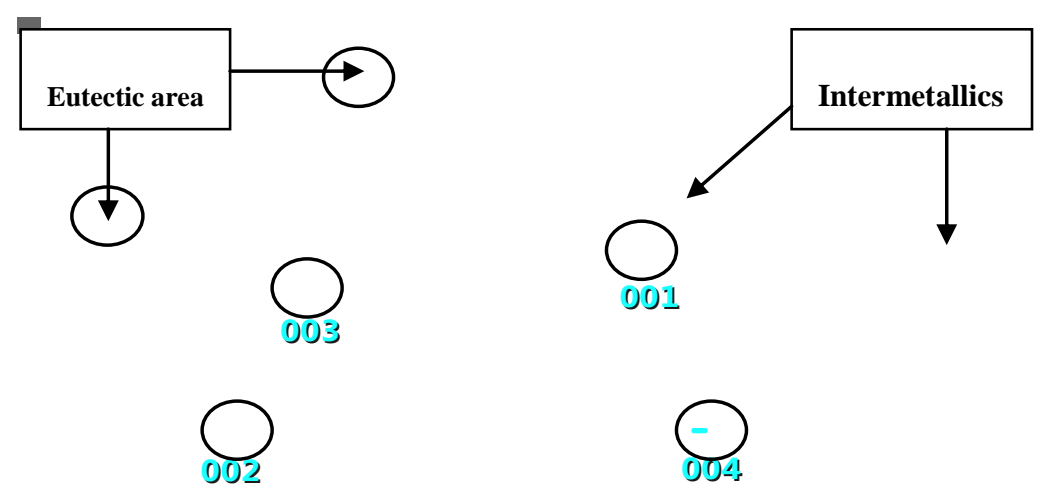
Figure 4: Representative SEM micrograph of as-cast Mg-14Li-3Al-3Ce alloy with four different random EDX points.

Figures 5 (a), (b), (c), \& (d) depicts the EDX spectrum of the as-cast Mg-14Li-3Al-3Ce alloys composition at four randomly selected points on the micrograph. Table 2 shows varying percentage composition of the elements in the alloy lattice at the four random selected points.

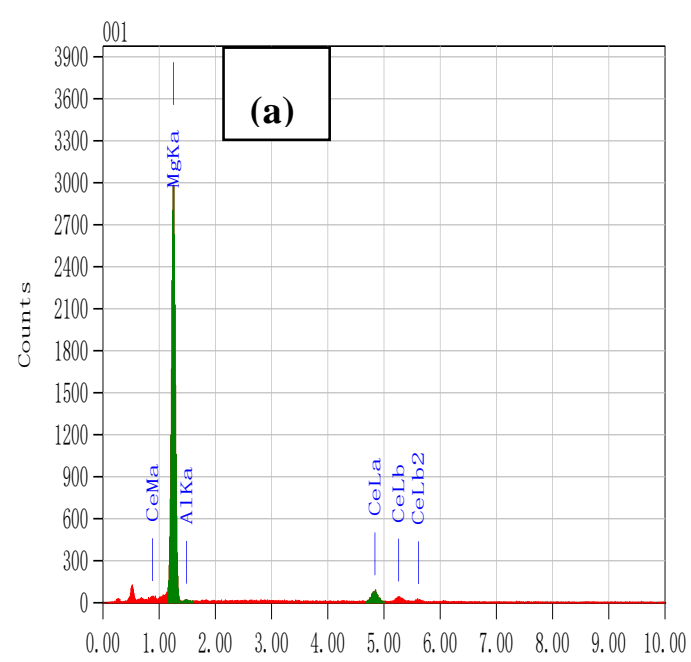

$\mathrm{kel}$

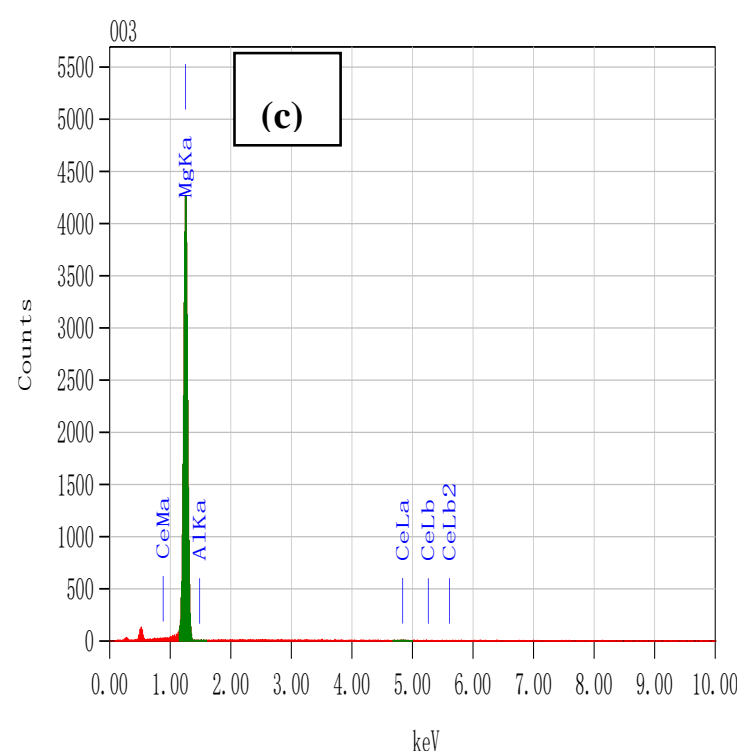

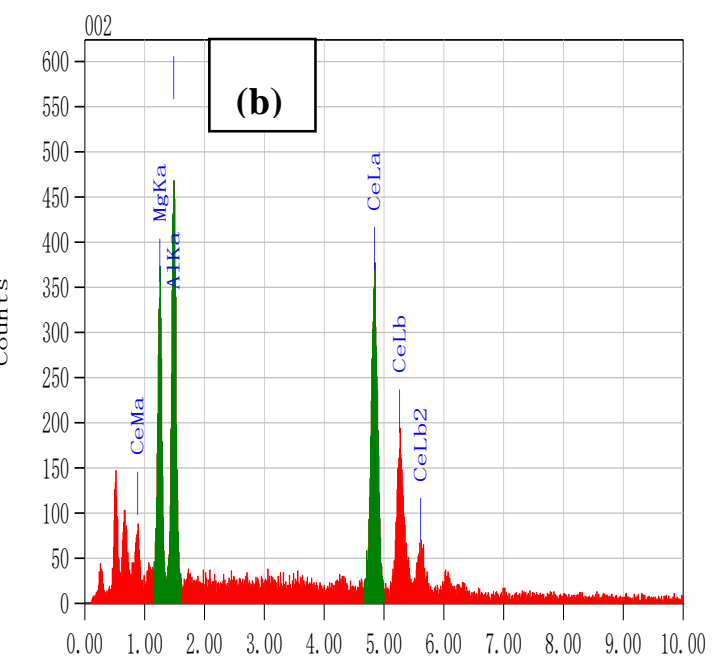

$\mathrm{keV}$

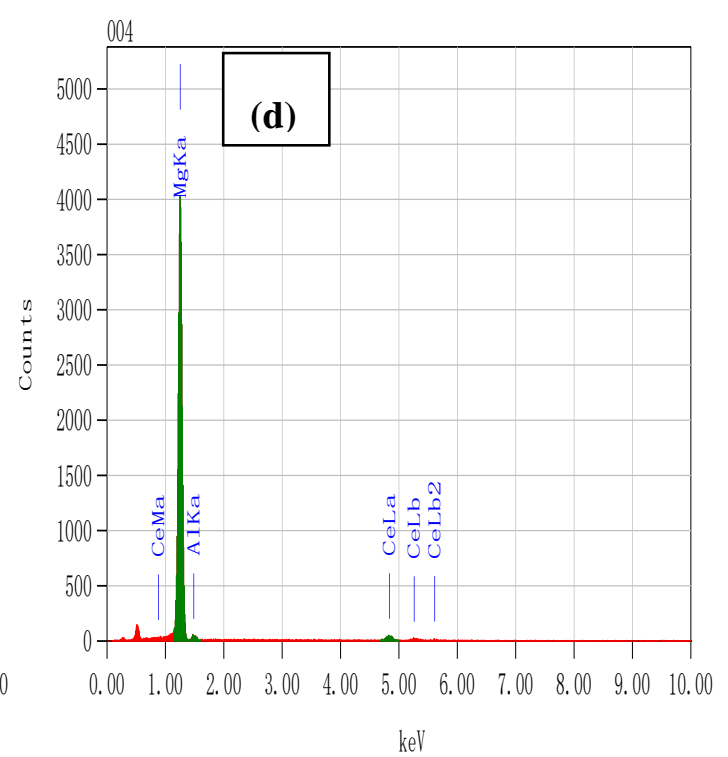

Figure 5: EDX Spectrum of as-cast $\mathrm{Mg}-14 \mathrm{Li}-3 \mathrm{Al}-3 \mathrm{Ce}$ alloy at randomly selected points: (a) 001, (b) 002, (c) 003, and (d) 004. 
Table 2: EDX composition of as-cast Mg-14Li-3Al-3Ce alloy showing SEM micrographs at selected random points in Figure 4

\begin{tabular}{|l|c|c|c|c|c|c|c|c|}
\hline \multirow{2}{*}{ EDS } & \multicolumn{5}{|c|}{ Weight (\%) } & \multicolumn{3}{c|}{ Atomic(\%) } \\
Point & \multicolumn{2}{|c|}{ (\%) } & \multicolumn{3}{c|}{} \\
\hline & $\mathrm{Mg}$ & $\mathrm{Al}$ & $\mathrm{Ce}$ & Total & $\mathrm{Mg}$ & $\mathrm{Al}$ & $\mathrm{Ce}$ & Total \\
\hline 001 & 82.51 & 0.00 & 17.49 & 100.00 & 96.45 & 0.00 & 3.55 & 100.00 \\
\hline 002 & 14.28 & 19.88 & 65.84 & 100.00 & 32.75 & 41.06 & 26.19 & 100.00 \\
\hline 003 & 99.08 & 0.00 & 0.92 & 100.00 & 99.84 & 0.00 & 0.16 & 100.00 \\
\hline 004 & 89.57 & 1.25 & 9.17 & 100.00 & 97.05 & 1.22 & 1.72 & 100.00 \\
\hline
\end{tabular}

Varied composition is attributed to different solubility rate of the elements in $\mathrm{Mg}-\mathrm{Li}$ alloy and the strength of the bonds between the composite elements. Cerium has got very little solubility rate in the Magnesium alloy; hence dominantly exist inform of large white particles (Figures 3 and 4). The SEM micrograph in Figure 4 at point 002 depicts Cerium exists at $65.84 \%$ wt and $41.06 \%$ at in the alloy lattice. Points 001, 003 and 004 mainly consist of second phase intermetallic precipitates and coherent $\beta$-phase regions. The intermetallics formed identified by the X-ray spectrum are displayed by Figure 2. The formation of binary intermetallics/precipitates is attributed to the large electronegative difference between the elements resulting in high affinity between Magnesium, Aluminium and Cerium atoms. Cerium particles remains undissolved in the alloy owing to its low solubility rate (approximately $0.11 \%$ at) in Magnesium alloy; but preferentially forms Cerium-intermetallic precipitates with other elements owing to its high affinity to the alloy composites. The dominant coherent $\beta$-phase in Mg-14Li-3Al- 
3Ce alloy imparts valuable effects on the alloys castability and formability. This is attributed to the eutectic nature of the alloys as they do not undergo semi-solid state but transforms directly from liquid to solid solution[13].

\subsection{Mechanical properties}

The as-cast Mg-14Li-3Al-3Ce alloy exhibited Yield Strength (YS) of 72.6MPa, Ultimate Tensile Strength (UTS) of 104.3MPa with an elongation of 5.8\%. The alloys that were aged for 5 and 10 hours exhibited YS of 78.1MPa, UTS of 111.6MPa, strain elongation of $22.5 \%$; and YS of $84.2 \mathrm{MPa}$, UTS of $118.8 \mathrm{MPa} \&$ strain elongation of $24.1 \%$ respectively. The $\mathrm{Mg}-8 \mathrm{Li}-3 \mathrm{Al}-3 \mathrm{Ce}$ alloy that was aged for 15 hoursand cooled by water at $25^{\circ} \mathrm{C}$ had YS of $105.5 \mathrm{MPa}$, UTS of $136.8 \mathrm{MPa}$ with strain elongation rate of $19.2 \%$ (Figures $6,7 \& 8$ ). Significantly, the more the aging duration was prolonged, the greater the yield strength and ultimate tensile strength attained by the Mg-14Li-3Al-3Ce alloys (Figure 7). Increased ductility is exhibited by the 5 and 10 hours aged alloys, but decreases for the 15 hours aged and water cooled alloy (Figure 8). Based on the fact that $\mathrm{Mg}-14 \mathrm{Li}-3 \mathrm{Al}-3 \mathrm{Ce}$ alloys formed are in the predominantly softer $\beta$-phase of $\mathrm{Mg}-\mathrm{Li}$ alloy, this factor potentially contributes to the alloys increased ductility. Increased ductility is also enhanced by the homogenously distributed coherent intermetallic precipitates formed during aging. Refined precipitates give rise to higher microstructure anisotropy that yields homogenized microstructure and crystallization activating higher ductility. The 15 hours aged alloy followed by fast-cooling exhibited decreased ductility due to the induced brittle intermetallics and limitation of dislocations motion caused by dynamic strain aging[18, 34]. Aged Mg-14Li-3Al-3Ce alloys exhibits a significant increased tensile strength (Figures 6 and 7). Increased yield strength and ultimate tensile strength in Figure 7 is attributed to both dynamic strain aging and fast-cooling effects. Fast-cooling by water produces supersaturated solid solution of the alloying elements in 
Mg-14Li-3Al-3Ce alloy. Aging the alloys activates the precipitation series of dispersed meta-stable and stable precipitate phases which offer greater resistance to dislocation propagation during the aging process[35]. The dispersed second phase intermetallic precipitates formed in the $\mathrm{Mg}-14 \mathrm{Li}-3 \mathrm{Al}-3 \mathrm{Ce}$ alloy reduce the rate of dislocations motion by acting as strong pinning sites. Owing to this factor, the tensile strength of the alloys is enhanced. They also activate localised internal stress fields from the small coherent $\beta$ 'phases (Guinier-Preston Zones) that increase the alloys strength[36]. In addition, dynamic aging strengthening effect can be ascribed to dislocations cutting through the Mg-14Li-3Al-3Ce alloys particles by the age hardening relationships[37]:

$$
\begin{gathered}
\tau=\frac{\pi r y}{b L} \\
\text { Or } \\
\tau=\frac{G b}{L-2 r}
\end{gathered}
$$

Where: $\tau$ is $\mathrm{Mg}-14 \mathrm{Li}-3 \mathrm{Al}-3 \mathrm{Ce}$ alloy strength, $r$ is the second phase precipitate radius, and $\gamma$ is the alloy lattice surface energy. The Burgers vector magnitude is $b, L$ is the spacing between precipitate pinning sites in the lattice and $G$ is lattice shear modulus. Equation (3) supports the direct proportionality relationship that is displayed by strength of the $\mathrm{Mg}-14 \mathrm{Li}-3 \mathrm{Al}-3 \mathrm{Ce}$ alloys to the radius, $r_{s}$ of the formed precipitates. These dislocations cut through alloys precipitates that have got smaller radius. As the radius of the precipitates/particles increases, dislocation bowing is activated thus facilitating increased work hardening rate as illustrated by Equation 4[37]. The dispersed intermetallics formed from the supersaturated second phase precipitates triggers high diffusion rates in the $\mathrm{Mg}-14 \mathrm{Li}-3 \mathrm{Al}-3 \mathrm{Ce}$ alloys inducing increased homogenous precipitation strengthening effect. However, increased grain refinement and 
recrystallization that may occur during fast-cooling, limits the critical precipitation role of the induced second phase precipitates. This is attributable to the high number of small coherent precipitates formed that imparts different strengthening effects on the $\mathrm{Mg}$ 14Li-3Al-3Ce alloys. Thus it is possible that not all second phase precipitates formed contribute to the entire strengthening effects of the Mg-14Li-3Al-3Ce alloy[25, 38]. Increased yield strengths and ultimate tensile strengths for the aged and fast-cooled Mg14Li-3Al-3Ce alloys is also attributable to Hall-Petch theory mechanism equation stated[39]:

$$
\sigma=\sigma_{0}+K d^{-1 / 2}
$$

Where: $\sigma$ is the yield stress of Mg-14Li-3Al-3Ce alloy; $\sigma_{0}$ the yield stress of a single crystal that resists dislocation movement (frictional resistance) in the $\mathrm{Mg}-14 \mathrm{Li}-3 \mathrm{Al}-3 \mathrm{Ce}$ alloy; $K$ is the hardening contribution from the grain boundary (constant factor) and $d$ is average grain size diameter of each Mg-14Li-3Al-3Ce alloy particle. From equation (5), higher percentage of refined grains in the aged $\mathrm{Mg}-14 \mathrm{Li}-3 \mathrm{Al}-3 \mathrm{Ce}$ alloys induces more grain boundaries that act as impediments to the dislocation propagation. As a result, the tensile strength of the alloys is increased. When the dislocations initiated by aging process pile up at the grain boundary, their quantity can be determined by using the relationship[37]:

$$
n=\frac{k \pi \tau_{s} D}{4 G b}
$$

Where: $n$ is the number of dislocations, $k$ is a constant factor (approximately unity) and $\tau_{s}$ is the average resolved shear stress of $\mathrm{Mg}-14 \mathrm{Li}-3 \mathrm{Al}-3 \mathrm{Ce}$ alloys. $D$ is average grain diameter of each alloy particle, $G$ is lattice shear modulus and $b$ is the burgers vector magnitude. From equation (6), the smaller the diameter of the Mg-14Li-3Al-3Ce alloys grain sizes, the lower the number of dislocations formed resulting to enhanced alloys 
strength. A summarized increasing trend in yield strength (YS), ultimate tensile strength (UTS) and ductility of aged $\mathrm{Mg}-14 \mathrm{Li}-3 \mathrm{Al}-3 \mathrm{Ce}$ alloys for 5 and 10 hours respectively is displayed by Figures 7 and 8 . Figures 7 and 8 also depict the increased yield strength and ultimate tensile strength with decreased ductility for the Mg-14Li-3Al-3Ce alloy that was aged for 15 hours and fast-cooled at room temperature. The values obtained are in agreement with the previous related studies on $\mathrm{Mg}$-Li-Al-RE based alloys.

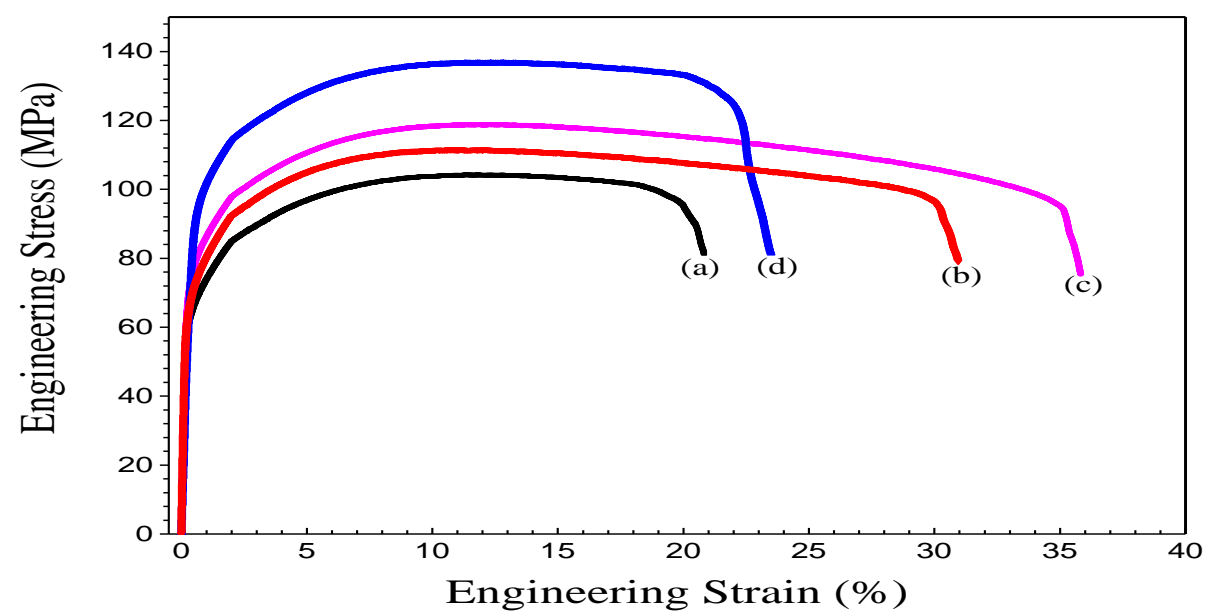

Figure 6: Engineering stress-strain curves of Mg-14Li-3Al-3Ce alloys: (a) As-cast, (b) Aged for 5 hours, (c) Aged for 10 hours, (d) Aged for 15 hours.

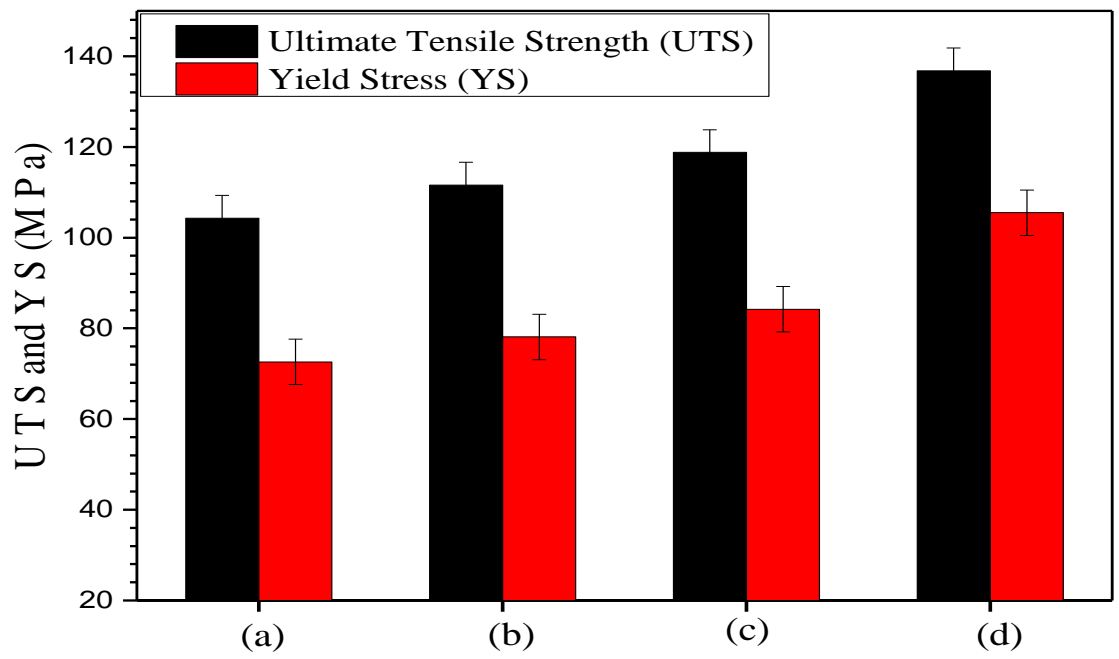

Mg-14Li-3Al-3Ce alloy samples 
Figure 7: Ultimate Tensile Strength (UTS) and Yield Stress (YS) of Mg-14Li-3Al-3Ce alloys: (a) As-cast, (b) Aged for 5 hours, (c) Aged for 10 hours, (d) Aged for 15 hours.

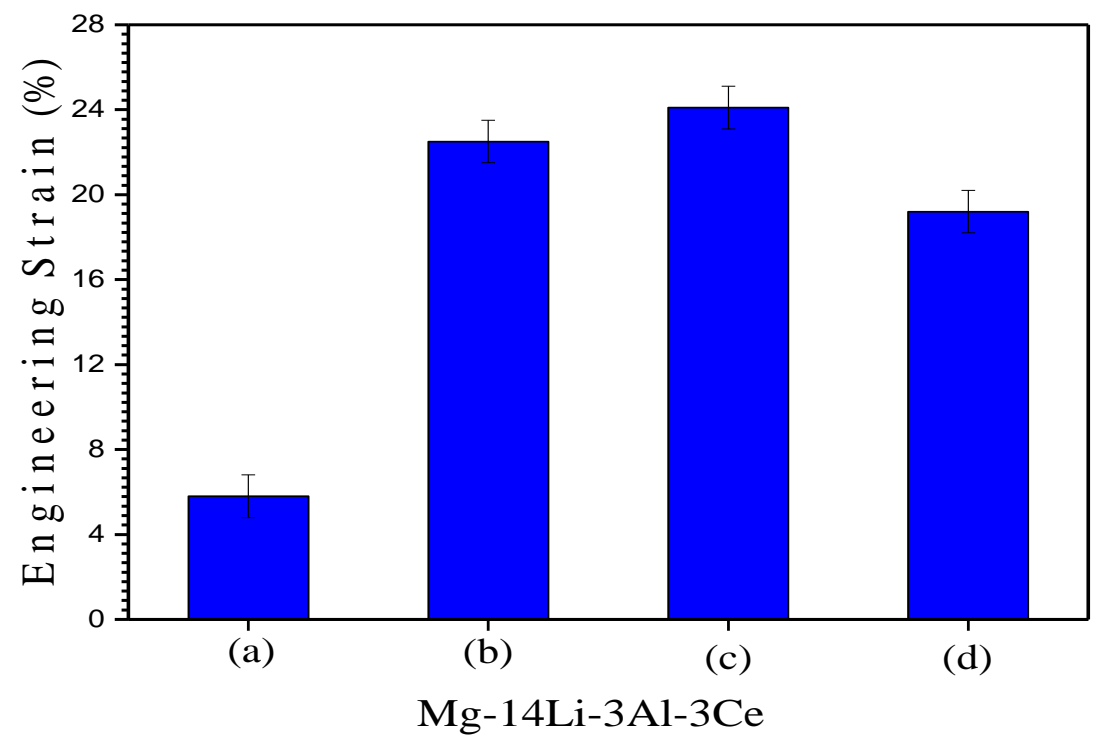

Figure 8: Engineering strain of Mg-14Li-3Al-3Ce alloys: (a) As-cast, (b) Aged for 5 hours, (c) Aged for 10 hours, (d) Aged for 15 hours.

The strain hardening index $(n)$ and true strain values are shown by Figure 9 and table 3 respectively. Strain hardening index derived from stress-strain curves in Figure 6 determines the formability and ductility of $\mathrm{Mg}-14 \mathrm{Li}-3 \mathrm{Al}-3 \mathrm{Ce}$ alloys and is theoretically summed up using the power law:

$$
\sigma_{T}=K \varepsilon_{T}^{n}(0 \leq n \geq 1)
$$

Where: $\sigma_{T}$ represents applied stress on the alloys, $K$ is the strength coefficient, $\varepsilon_{T}$ is the alloys strain and $n$ is the strain hardening index. The alloys undergo localized deformation (necking) activated by tensional forces; resulting in decreased crosssectional area which is attributable to strain hardening of $\mathrm{Mg}-14 \mathrm{Li}-3 \mathrm{Al}-3 \mathrm{Ce}$ alloys. Increased $n$-values for the 5 and 10 hours aged alloys signify higher elongation and ductility as a result of necking resistance by the alloys before fracture occurs. Thus Mg- 
14Li-3Al-3Ce alloys develop much improved formability upon increased aging duration. However, the 15 hours aged and fast-cooled Mg-14Li-3Al-3Ce alloy at $25^{\circ} \mathrm{C}$ exhibited reduced $n$-value justifying its decreased ductility. The values obtained were found to range between $0.20-0.50$ which is typical for the $\mathrm{Mg}$-Li based alloys[1, 40].

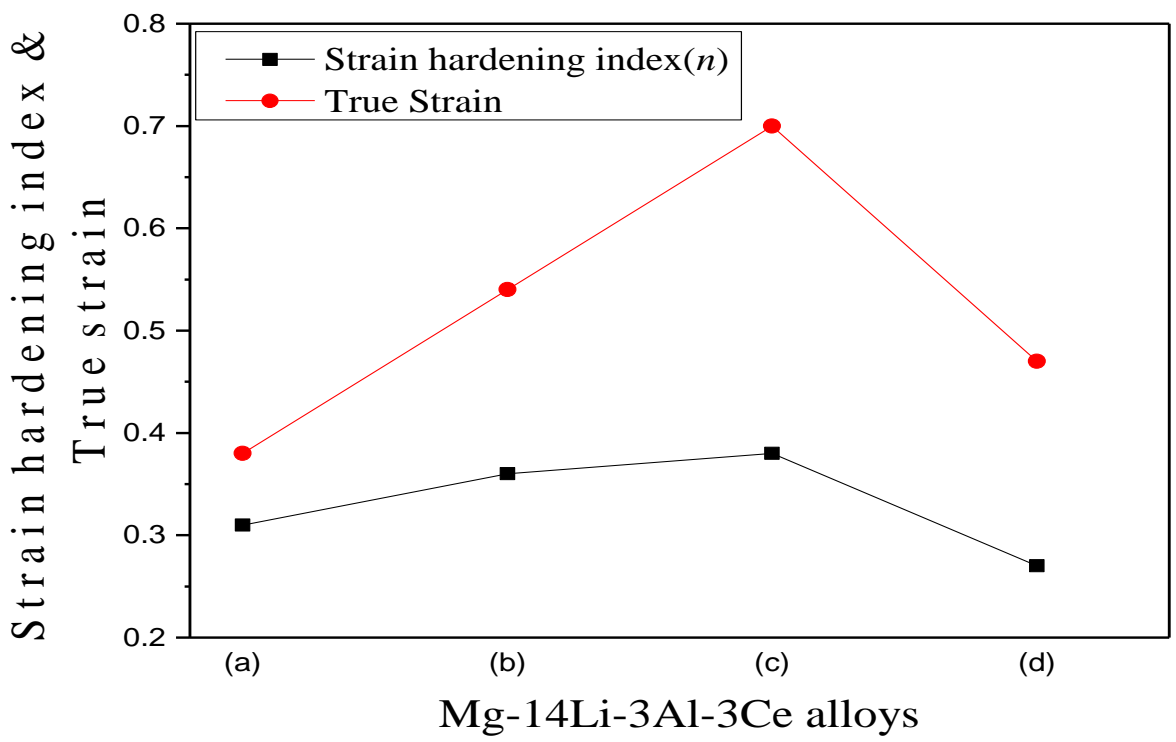

Figure 9: Strain hardening index $(n)$ and true strain of Mg-14Li-3Al-3Ce alloys: (a) Ascast, (b) Aged for 5 hours, (c) Aged for 10 hours, (d) Aged for 15 hours.

Table 3: Strain hardening index (n) and true strain of Mg-14Li-3Al-3Ce alloys

\begin{tabular}{|l|c|c|}
\hline \multicolumn{1}{|c|}{ Mg-14Li-3Al-3Ce alloy } & $\begin{array}{c}\text { Strain hardening index } \\
(n)\end{array}$ & $\begin{array}{c}\text { True strain } \\
\left(\mathrm{l} / l_{0}\right)\end{array}$ \\
\hline As-cast & 0.31 & 0.38 \\
\hline Aged 5 hrs & 0.36 & 0.54 \\
\hline Aged 10 hrs & 0.38 & 0.70 \\
\hline Aged15 hours and fast-cooled & 0.27 & 0.47 \\
\hline
\end{tabular}




\subsection{Fracture Tensile surface}

Figure 10 depicts the fracture surfaces of Mg-14Li-3Al-3Ce alloys. Figure 10 (a) and (b) displays densely populated micro-voids and dimples of varied sizes and shapes signifying ductile fracture. The numerous dimples and micro-voids are formed at the induced second-phase precipitates sites and/or locations during the aging process. Figures 10 (c) and (d) show propagated cleavage fractures initiated within the alloys grains get arrested at the grain boundaries. These fractures develop with prolonged aging time owing to increased plastic strain during aging. The main phases of the fracture surfaces of alloys consisted of dual mixtures of brittle and ductile fractures[41]. Partially brittle fractures were initiated by $\mathrm{Mg}_{17} \mathrm{Al}_{12}$ and $\mathrm{Mg}$-Ce precipitated phases [Figures 10 (c) and (d)] and ductile fractures got initiated by the soft $\beta$-Mg phases. Sharp cracks depicted in Figure 10 (d) were mostly likely initiated at the $\mathrm{Mg}_{12} \mathrm{Ce}, \mathrm{Al}_{11} \mathrm{Ce}$ precipitates and undissolved Cerium particles phases after breaking the grain boundaries of $\mathrm{Mg}$ 14Li-3Al-3Ce alloys. Minor contributions from discontinuous precipitates could have also initiated cracking and partial cleavage fractures on the alloy surfaces. From the fracture surfaces, it is noted that most dimples show cracked particles/precipitates at their ends. This signifies the initiation of propagation of intergranular fracture at the interface between the intermetallic precipitates and the alloy lattice matrix. Crack propagation occurs along grain boundaries that are embrittled by the induced intermetallics. This is consistence with the research study carried out by Wu et al.[19, 42]. The as-cast alloy surface in Figure 10 (a) exhibits ductile fracture. Alloys aged for 5 and 10 hours show dual characteristics of partially brittle and ductile (quasi-cleavage) fractures [Figures 10 (b) and (c)]. Pronounced Mg-14Li-3Al-3Ce alloy quasi-cleavage fractures and micro-cracks displayed in Figure 10 (d) are attributable to fast-cooling effects initiated by the coolant. 

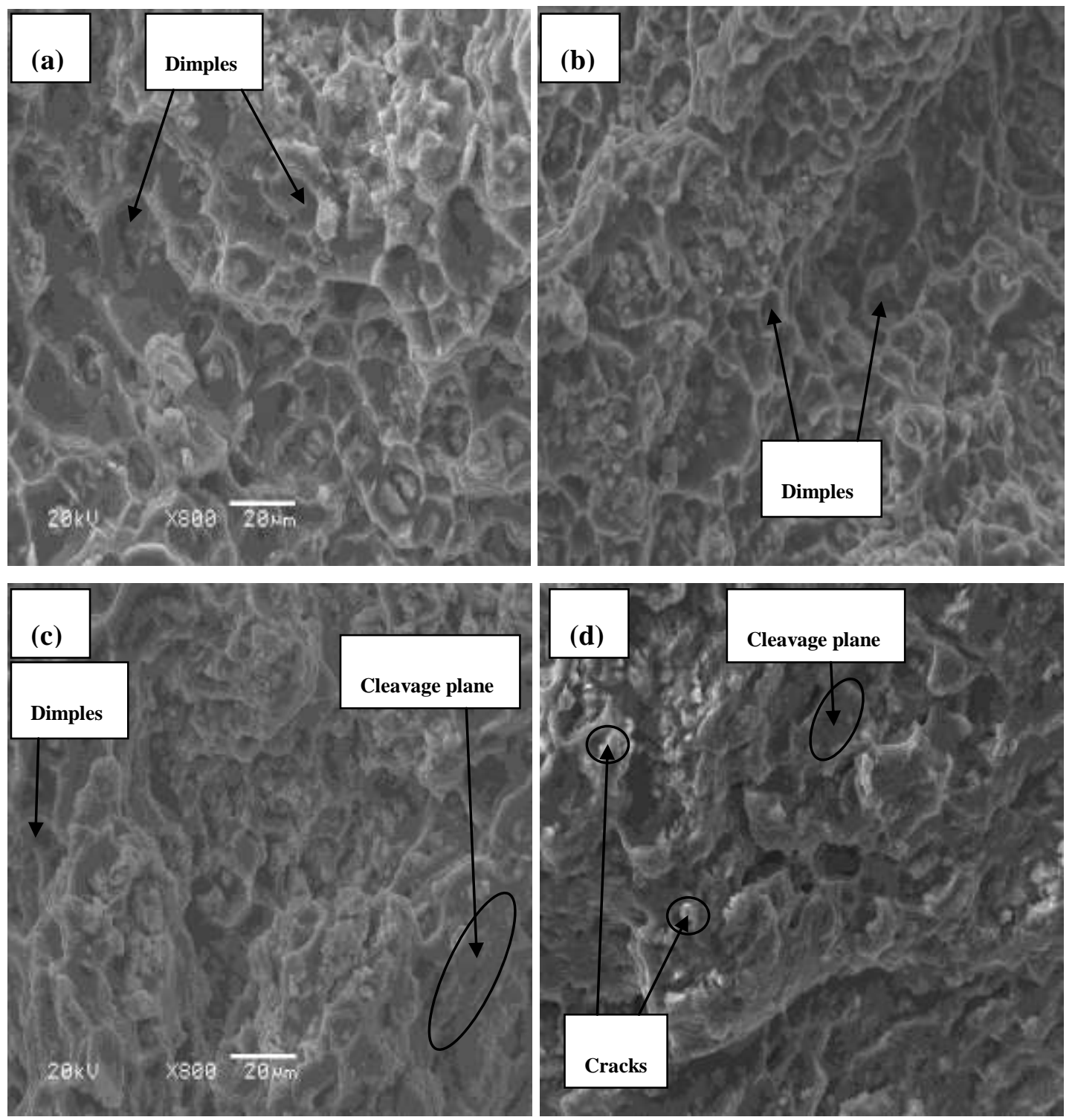

Figure 10: Fracture morphology of Mg-14Li-3Al-3Ce alloys: (a) As-cast, (b) Aged for 5 hours, (c) Aged for 10 hours, (d) Aged for 15 hours.

\subsection{Alloys Microhardness}

The micro-hardness values of as-cast, thermo-mechanically aged and fast-cooled Mg-14Li-3Al-3Ce alloys are shown in Figure 11. The as-cast alloy depicts hardness of 43.8HV. The 5 hours aged Mg-14Li-3Al-3Ce alloy exhibits hardness of 48.4HV while the 10 hours aged alloy depicts $55.8 \mathrm{HV}$ hardness magnitude. The 15 hours aged \& fastcooled alloy at $25^{\circ} \mathrm{C}$ exhibits micro-hardness magnitude of $61.3 \mathrm{HV}$. The trend shown by the Vickers hardness values conforms to the tensile yield strength and ultimate tensile 
strength of the alloys. Increased alloys hardness is noted with prolonged aging duration and cooling by water treatment. The 15 hours aged and fast-cooled alloy at $25^{\circ}$ Cexhibits the greatest hardness magnitude (Figure 11). Increased hardness is attributable to precipitation of second phase intermetallics formed in the alloy lattice. Increased hardness may also be due to solid solution strengthening during the alloys aging and water cooling processes[43]. Increased hardness as a result of solid solution strengthening is ascribed to the increased alloys internal stress.

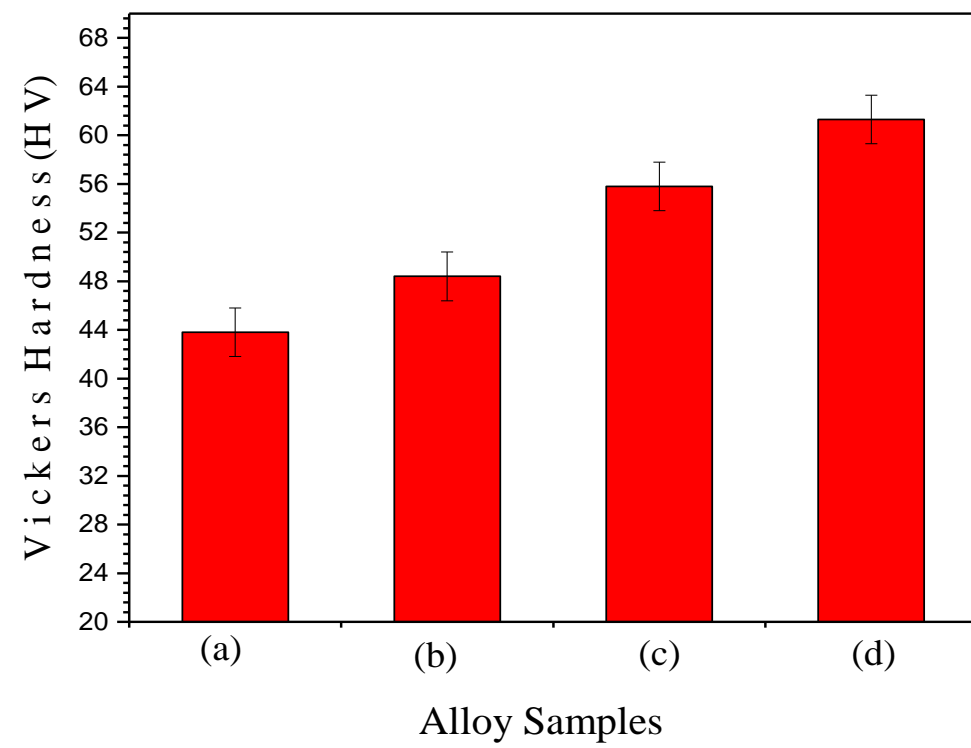

Figure 11: Vickers micro-hardness of Mg-14Li-3Al-3Ce alloys: (a) As-cast, (b) Aged for 5 hours, (c) Aged for 10 hours, (d) Aged for 15 hours.

\subsection{Conclusion}

- Aging and fast-cooling by water processing initiates the formation of thermal second phase intermetallics. The presence of $\mathrm{Mg}_{17} \mathrm{Al}_{12}, \mathrm{Mg}_{12} \mathrm{Ce}$ and $\mathrm{Al}_{11} \mathrm{Ce}$ precipitates induce grain refinement of $\mathrm{Mg}-14 \mathrm{Li}-3 \mathrm{Al}-3 \mathrm{Ce}$ alloys and enhance their tensile strength. However, the presence of excess Cerium particles does not 
contribute to further refinement of grains as it remains largely undissolved owing to its low solubility.

- The soft coherent $\beta-\mathrm{Mg}$ phase formed in the lattice improves the alloys ductility. This is attributed to the formation of fine lamellar structures and precipitates that are homogenously distributed in the lattice and favours enhanced ductility.

- Fracture morphology depicts as-cast alloys changing from ductile fracture to mixed ductile and partial-cleavage fractures upon aging and fast-cooling.

- Strain aging and fast-cooling effects enhance the tensile strengths and mechanical properties of the alloys. Significant strengthening achieved by the aged $\mathrm{Mg}$-14Li-3Al-3Ce alloys is attributable to solution and dynamic precipitation strengthening mechanisms.

\section{Acknowledgements}

This work was supported by the Natural National Science Foundation of China (NSFC) Funding [51371062 and U1460102], Natural Science Foundation of Heilongjiang, NSFHLJ [ZD201411], the Scientific Research Foundation for the Returned Overseas Chinese Scholars (Heilongjiang Province) and the Project for Innovative Talents of Science and Technology of Harbin [2014RFXXJ006].

\section{References}

[1] H. B. M. B. Avedesian, H., Magnesium and Magnesium Alloys (Asm Specialty Handbook). United States of America: ASM International, 1999.

[2] SAE International TM, "Magnesium for Automotive Components, Society of Automotive Engineers:," Warrendale, PA,, 2004. 
[3] S. Schumann, "The Paths and Strategies for Increased Magnesium Applications in Vehicles " Mater. Sci. Forum, vol. 488-489, pp. 1-8, 2005.

[4] B. Jiang, Q.-s. Yang, M.-x. Zhang, Q. Dong, R.-h. Li, and F.-s. Pan, "Grain refinement of Mg-Li-Al cast alloys by adding typical master alloys," Progress in Natural Science: Materials International, vol. 21, pp. 236-239, 2011.

[5] C.-H. Chiu, J.-Y. Wang, and H.-Y. Wu, "Microstructural characterization of a Mg-9\% Li-1\% Zn alloy," Materials transactions, vol. 47, pp. 966-970, 2006.

[6] P. Fei, Z. Qu, and R. Wu, "Microstructure and hardness of Mg-9Li-6Al-xLa $(\mathrm{x}=0,2,5)$ alloys during solid solution treatment," Materials Science and Engineering: A, vol. 625, pp. 169-176, 2/11/2015.

[7] T. Liu, S. Wu, S. Li, and P. Li, "Microstructure evolution of Mg-14\% Li-1\% Al alloy during the process of equal channel angular pressing," Materials Science and Engineering: A, vol. 460, pp. 499-503, 2007.

[8] G. Wu, Y. Fan, H. Gao, C. Zhai, and Y. P. Zhu, "The effect of Ca and rare earth elements on the microstructure, mechanical properties and corrosion behavior of AZ91D," Materials Science and Engineering: A, vol. 408, pp. 255-263, 11/5/ 2005.

[9] R. Pérez-Bustamante, A. Reyna-Cruz, D. C. Acosta-Peña, C. R. SantillánRodríguez, J. A. Matutes-Aquino, F. Pérez-Bustamante, et al., "Effect of cerium/lanthanum addition on microstructure and mechanical properties of Al7075 alloy via mechanical alloying and sintering.," J. of Rare Earths.,, vol. 34, pp. 420-427, 4// 2016;

[10] N. Stanford, D. Atwell, A. Beer, C. Davies, and M. Barnett, "Effect of microalloying with rare-earth elements on the texture of extruded magnesiumbased alloys," Scripta materialia, vol. 59, pp. 772-775, 2008. 
[11] K. Hantzsche, J. Bohlen, J. Wendt, K. Kainer, S. Yi, and D. Letzig, "Effect of rare earth additions on microstructure and texture development of magnesium alloy sheets," Scripta Materialia, vol. 63, pp. 725-730, 2010.

[12] J. Bohlen, S. Yi, D. Letzig, and K. U. Kainer, "Effect of rare earth elements on the microstructure and texture development in magnesium-manganese alloys during extrusion," Materials Science and Engineering: A, vol. 527, pp. 70927098, 2010.

[13] G. S. Song, M. Staiger, and M. Kral, "Some new characteristics of the strengthening phase in $\beta$-phase magnesium-lithium alloys containing aluminum and beryllium.," Mater. Sci. Eng.: A, vol. 371, pp. 371-376, 2004;.

[14] T. Wang, R. Wu, M. Zhang, L. Li, J. Zhang, and J. Li, "Effects of calcium on the microstructures and tensile properties of $\mathrm{Mg}-5 \mathrm{Li}-3 \mathrm{Al}$ alloys," Materials Science and Engineering: A, vol. 528, pp. 5678-5684, 7/15/ 2011.

[15] J. Ryan, . Hooper, Michael,. Lee, Zachary Bryan, and Michele, Viola, Manuel., "The Effect of Indium Additions on Mg-Li and Mg-Li-Al Alloys. ," Met. and Mater Trans. A.,, vol. 45(1):, 2014.

[16] M. Mabuchi, Y. Chino, H. Iwasaki, T. Aizawa, and K. Higashi, "The grain size and texture dependence of tensile properties in extruded Mg-9Al-1Zn," Materials transactions-JIM, vol. 42, pp. 1182-1189, 2001.

[17] V. V. George, ASM Handbook: Metallography And Microstructures vol. Vol 9. USA: ASM International 2004;

[18] R. Wu, Z. Qu, and M. Zhang, "Effects of the addition of Y in Mg-8Li-(1,3)Al alloy," Materials Science and Engineering: A, vol. 516, pp. 96-99, 8/15/ 2009.

[19] L. Wu, C. Cui, R. Wu, J. Li, H. Zhan, and M. Zhang, "Effects of Ce-rich RE additions and heat treatment on the microstructure and tensile properties of $\mathrm{Mg}-$ 
Li-Al-Zn-based alloy.," Mater. Sci. Eng,: A, vol. 528, pp. 2174-2179, 2/25/ 2011;

[20] L. Gao, R. S. Chen, and E. H. Han, "Effects of rare-earth elements Gd and Y on the solid solution strengthening of $\mathrm{Mg}$ alloys," Journal of Alloys and Compounds, vol. 481, pp. 379-384, 7/29/ 2009.

[21] J. Zhang, Q. Ma, and F. Pan, "Effects of trace Er addition on the microstructure and mechanical properties of $\mathrm{Mg}-\mathrm{Zn}-\mathrm{Zr}$ alloy," Materials \& Design, vol. 31, pp. 4043-4049, 10// 2010.

[22] H. Dong, L. Wang, Y. Wu, and L. Wang, "Effect of Y on microstructure and mechanical properties of duplex Mg-7Li alloys.," J. Alloys Compd.,, vol. 506, pp. $468-474,9 / 10 / 2010$.

[23] R. Ding, C. Chung, Y. Chiu, and P. Lyon, "Effect of ECAP on microstructure and mechanical properties of ZE41 magnesium alloy," Materials Science and Engineering: A, vol. 527, pp. 3777-3784, 6/25/ 2010.

[24] C. L. Mendis, K. Oh-ishi, Y. Kawamura, T. Honma, S. Kamado, and K. Hono, "Precipitation-hardenable $\mathrm{Mg}-2.4 \mathrm{Zn}-0.1 \mathrm{Ag}-0.1 \mathrm{Ca}-0.16 \mathrm{Zr} \quad$ (at.\%) wrought magnesium alloy," Acta Materialia, vol. 57, pp. 749-760, 2// 2009.

[25] J. H. Li, G. Sha, T. Y. Wang, W. Q. Jie, and S. P. Ringer, "Precipitation microstructure and age-hardening response of an $\mathrm{Mg}-\mathrm{Gd}-\mathrm{Nd}-\mathrm{Zn}-\mathrm{Zr}$ alloy," Materials Science and Engineering: A, vol. 534, pp. 1-6, 2/1/ 2012.

[26] S. K. Panigrahi, W. Yuan, R. S. Mishra, R. DeLorme, B. Davis, R. A. Howell, et al., "A study on the combined effect of forging and aging in $\mathrm{Mg}-\mathrm{Y}-\mathrm{RE}$ alloy," Materials Science and Engineering: A, vol. 530, pp. 28-35, 12/15/ 2011. 
[27] M. A. J. Easton, S. D. H., "A model of grain refinement incorporating alloy constitution and potency of heterogeneous nucleant particles;" Acta Materialia;, vol. 49, 2001.

[28] M. C. C. D. Duly, and Y. Brechet:, "Morphology and chemical nanaoanalysis of discontinous precipitation in Mg-Al alloys-II Regular growth.," Acta Metall. Mater., vol. 42, pp. 3855-3863, 1994.

[29] M. C. C. D. Duly, and Y. Brechet:, "Morphology and chemical nanoanalysis of discontinuous precipitation in $\mathrm{Mg}-\mathrm{Al}$ alloysMorphology and Chemical nanoanalysis of disxontinous precipitation in Mg-Al alloys-I. Regular growth;," Acta Metall. Mater., , vol. 42, pp. 3843-3854, 1994.

[30] J. P. S. D. Duly, and Y. Brechet;, "On the competition between continuous and discontinuous in precipitations in binary Mg-Al alloys.," Acta Metall. Mater., , vol. 43, pp. 101-106, 1995;.

[31] J. Geng and J. Nie, "Microstructure and mechanical properties of extruded Mg1Ca-1Zn-0.6Zr alloy.," Mater. Sci. Eng.: A, vol. 653, pp. 27-34, 1/20/ 2016;.

[32] T. Hama, Y. Kariyazaki, N. Hosokawa, H. Fujimoto, and H. Takuda, "Workhardening behaviors of magnesium alloy sheet during in-plane cyclic loading.," Mater. Sci. Eng.: A, vol. 551, pp. 209-217, 8/15/ 2012;.

[33] R. Wu and M. Zhang, "Microstructure, mechanical properties and aging behavior of $\mathrm{Mg}-5 \mathrm{Li}-3 \mathrm{Al}-2 \mathrm{Zn}-\mathrm{xAg}, "$ Materials Science and Engineering: A, vol. 520, pp. $36-39,9 / 15 / 2009$.

[34] Q. Shi, L. Bian, W. Liang, Z. Chen, F. Yang, and Y. Wang, "Effects of adding Al-Si eutectic alloy and hot rolling on microstructures and mechanical behavior of Mg-8Li alloys," J. Alloys Compd.,, vol. 631, pp. 129-132, 5/15/ 2015. 
[35] R. Wu, Wang, Gu., Murr, L. E., Han, W., Zhang Zhongwu, Zhang Milin, and Yan, Y., "Recent progress in magnesium-lithium alloys.," Inter. Mater. Reviews;, vol. 60(2):, 2015,.

[36] Jian-Feng Nie., " Precipitation And Hardening In Magnesium Alloys.," The Minerals, Metals \& Materials Society and Asm International; Clayton, Australia., vol. 43, pp. 3891-3939, 2012.

[37] S. Queyreau, G. Monnet, and B. Devincre, "Orowan strengthening and forest hardening superposition examined by dislocation dynamics simulations," Acta Materialia, vol. 58, pp. 5586-5595, 10// 2010.

[38] Y. Lu, A. R. Bradshaw, Y. L. Chiu, and I. P. Jones, "The role of precipitates in the bio-corrosion performance of $\mathrm{Mg}-3 \mathrm{Zn}$ in simulated body fluid," Journal of Alloys and Compounds, vol. 614, pp. 345-352, 11/25/ 2014.

[39] N. Hansen, "Hall-Petch relation and boundary strengthening," Script Mater., vol. 51, pp. 801-806, 10// 2004.

[40] A. S. Argon, Strengthening Mechanisms in Crystal Plasticity;. United States of America: Oxford University Press, September 2007;

[41] A. Pineau, A. A. Benzerga, and T. Pardoen, "Failure of metals I: Brittle and ductile fracture," Acta Materialia, vol. 107, pp. 424-483, 4/1/ 2016.

[42] Z. Trojanová, Z. Száraz, P. Palček, and M. Chalupová, "Magnesium Alloys Based Composites," Magnesium alloys-Design, Processing and Properties. Ed. F. Czerwinski, INTECH, pp. 501-526, 2011.

[43] A. M. Abrão, B. Denkena, J. Köhler, B. Breidenstein, T. Mörke, and P. C. M. Rodrigues, "The influence of heat treatment and deep rolling on the mechanical properties and integrity of AISI 1060 steel," Journal of Materials Processing Technology, vol. 214, pp. 3020-3030, 12// 2014. 